\title{
Exclusive enteral nutrition versus corticosteroids for treatment of pediatric Crohn's disease: a meta-analysis
}

\author{
$\mathrm{Yu} \mathrm{Yu}^{1} \cdot$ Kang-Chen $\mathrm{Chen}^{2} \cdot$ Jie Chen $^{1} \mathbb{0}$
}

Received: 23 May 2018 / Accepted: 19 October 2018 / Published online: 21 January 2019

(C) The Author(s) 2019

\begin{abstract}
Background Many studies have examined the effects of exclusive enteral nutrition (EEN) in children with Crohn's disease (CD), but corticosteroids are considered a superior therapy and are frequently used in China. This meta-analysis aims to compare the efficacy of EEN with corticosteroids in treating pediatric CD.

Methods A comprehensive retrieval from medical databases, including PubMed, EMBASE, MEDLINE, Web of Science, Wanfang data, VIP and CNKI, was performed using the search terms "diet therapy", "exclusive enteral nutrition", "Crohn's disease", "inflammatory bowel diseases", "child" and "pediatrics" from January 1990 to April 2017.

Results We included 18 studies from 1329 identified sources in this meta-analysis. EEN was as effective as corticosteroids in inducing remission rate of children suffering from $\mathrm{CD}(\mathrm{OR}=1.35 ; 95 \% \mathrm{CI} 0.90,2.10 ; P=0.14)$. Nevertheless, patients who received EEN were more likely to achieve both endoscopic mucosal healing $(\mathrm{OR}=5.24 ; 95 \% \mathrm{CI} 2.06,13.37 ; P=0.0005)$ and histological mucosal healing $(\mathrm{OR}=4.78 ; 95 \%$ CI $1.89,12.08 ; P=0.0009)$ than those who received corticosteroids; the Pediatric Crohn's Disease Activity Index was lower [mean difference (MD) $=-3.67 ; 95 \%$ CI $-4.91,-2.43$ ] and weight gain was higher ( $\mathrm{MD}=1.92 ; 95 \% \mathrm{CI} 0.02,3.83 ; P=0.05)$ in those patients who received $\mathrm{EEN}$ than in those who received corticosteroids. No difference was found in relapse rate $(\mathrm{OR}=0.57 ; 95 \% \mathrm{CI} 0.25,1.29 ; P=0.18)$, height for age or body mass index between the patients treated with EEN and corticosteroids at the 1-year end point.

Conclusions This meta-analysis reveals that there is no significant difference between EEN and corticosteroids in the efficacy of inducing remission rate of $\mathrm{CD}$ in a pediatric population, but EEN is superior to corticosteroids in improving short-term mucosal inflammation and reducing the PCDAI index.
\end{abstract}

Keywords Children · Corticosteroids · Crohn's disease · Exclusive enteral nutrition · Inflammatory bowel disease · Nutrition

\section{Introduction}

Crohn's disease (CD) is a chronic relapsing inflammatory condition of the gastrointestinal tract. Causes of $\mathrm{CD}$ still remain unclear, but it is thought to result from

Electronic supplementary material The online version of this article (https://doi.org/10.1007/s12519-018-0204-0) contains supplementary material, which is available to authorized users.

Jie Chen

hzcjie@zju.edu.cn

1 Department of Gastroenterology, Children's Hospital, Zhejiang University School of Medicine, 3333 Binsheng Road, Binjiang District, Hangzhou 310051, China

2 First Affiliated Hospital, Zhejiang University School of Medicine, 79 Qingchun Road, Shangcheng District, Hangzhou 310002, China an interaction of individuals' genetics factors, epigenetic factors, microbial exposure, immune response and environment factors [1-4]. Approximately, 25\% of patients are diagnosed with $\mathrm{CD}$ before the age of 18 years [5], and the incidence of pediatric $\mathrm{CD}$ is increasing in both developed and developing nations [6, 7]. The goals of treatment in pediatric $\mathrm{CD}$ are to induce and maintain remission, relieve symptoms and optimize growth, while minimizing side effects [8].

After an accidental discovery in the 1970s that exclusive enteral nutrition (EEN) could induce remission of $\mathrm{CD}$, EEN has provided an innovative way to induce remission and optimize nutrition following diagnosis [9]. In 2014, the European Society of Pediatric Gastroenterology, Hepatology and Nutrition (ESPGHAN) and the European Crohn's and Colitis Organization (ECCO) issued revised consensus guidelines, recommending that 
EEN be considered as the first-line induction therapy for children with CD [10]. For induction of remission, patients were treated with EEN via the oral route or nasogastric tube feeding for approximately 6-8 weeks. Additionally, only chewing gum and water were allowed [11-13]. The dietary sources of protein included elemental, semi-elemental and polymeric diets, but various levels of proteins or lipids seem to not have much impact on efficacy [14-16].

Corticosteroids have been considered a major therapeutic option to induce remission in patients with active $\mathrm{CD}$, achieving a clinical remission in $60-91 \%$ of treated patients [1]. However, side effects of corticosteroids, such as Cushing appearance, bone demineralization and severe growth retardation, can be harmful to children's natural physical development [17]. In addition, evidence-based medicine supports that EEN therapy has fewer adverse events and lower side effect rates than corticosteroids [18]. EEN therapy was also suggested to be more effective in children than adults [19].

Two meta-analyses $[18,20]$ concluded that EEN, as a primary therapeutic approach for $\mathrm{CD}$, showed no significant difference from corticosteroids in inducing clinical remission. In contrast, two other meta-analyses [21, 22] concluded that patients' remission rates with corticosteroids were statistically superior to that with EEN. Although many studies have compared short-term remission rates between patients treated with corticosteroids and EEN, few studies have focused on the relapse rate in long-term follow-up, especially in children. Endoscopic sustained mucosal healing in Crohn's disease was reported to be associated with longer remission time, less inflammatory activity and decreased hospitalization rates $[23,24]$; corticosteroids were thought to be associated with poor mucosal healing [25], while EEN was effective in inducing mucosal remission [26]. Few meta-analyses have been performed comparing the differences in efficacy of these two therapies on mucosal healing, and we still do not know whether EEN or corticosteroids will prolong the time that pediatric patients with $\mathrm{CD}$ remain in remission.

EEN versus placebo-controlled experiments cannot be carried out in pediatric patients with CD because of difficulty in passing ethical review, and any "placebo" which was nutritionally complete to sustain nutrition during treatment would be regarded as EEN. As a result, most studies have chosen corticosteroid therapy as the control group. In this meta-analysis, we compared the remission rates between two therapy groups at 8 weeks and relapse rates at 1 year. We also included more high-quality studies and further evaluated the effects of two therapeutic strategies on mucosal healing, nutritional status and growth patterns.

\section{Methods}

\section{Data sources and search strategy}

We conducted literature retrieval on PubMed, EMBASE and MEDLINE, Web of Science from January 1990 to April 2017. The search terms "diet therapy" and "exclusive enteral nutrition" were combined using "OR", the search terms "inflammatory bowel diseases" and "Crohn's disease" were combined using "OR", and the search terms "pediatric" and "child" were combined using "OR". These three groups were then combined using "AND". For example, searching in PubMed: ((( pediatric[MeSH]) OR child[MeSH])) AND ((exclusive enteral nutrition[MeSH]) OR diet therapy[MeSH])) AND ((Crohn disease[MeSH]) OR inflammatory bowel diseases[MeSH]). Filters: publication date from 1990/01/01 to 2017/04/01. Language restrictions were not imposed. We also searched the literature in Wanfang data, VIP and China National Knowledge Internet with Chinese words for the same keywords and the same time span.

\section{Selection criteria}

Two investigators (YY and CK) independently screened the titles, abstracts and full texts using the search strategy mentioned above. We included studies that: (1) were RCTs or observational; (2) enrolled pediatric patients (under the age of 18 years) with CD; and (3) compared systemic corticosteroid drugs (prednisone, prednisolone) with EEN (polymeric formula, semi-elemental formula or elemental formula). Patients in the EEN arm were not to receive any other medication, and patients receiving corticosteroids were to be treated only with corticosteroids, or the same treatments were to be taken in both comparator arms in similar ways. Studies were excluded in any case when articles (1) did not give a precise definition of remission, (2) provided insufficient data for the outcomes of interest or (3) did not contain at least one clearly defined corticosteroids comparator arm. If a literature result was reported several times, we included the study that corresponded to the longest duration or had the largest sample size.

\section{Outcome measures}

The primary outcome measures were induced remission rate (percentage of subjects achieving remission after 6-8 weeks of treatment) and relapse rate (percentage of subjects relapsing at 1-year end point of follow-up). The secondary outcomes were collected at baseline and after the induced treatment, e.g., inflammation index including the Pediatric Crohn's Disease Activity Index (PCDAI) [27], C-reactive 
protein (CRP) and erythrocyte sedimentation rate (ESR); growth parameters such as weight and length; mucosal healing [endoscopic lesions were assessed according to a validated score standard (Crohn's Disease Endoscopic Index of Severity, CDEIS) [28] and histological lesions were assessed according to a scoring system previously validated [29]. The data on height for age and body mass index (BMI) were collected both at baseline and at the 1-year end point. Endoscopic mucosal healing or histological mucosal healing was separately defined as a decrease in endoscopic or histological scores by $50 \%$ or more when compared with baseline values.

\section{Quality assessment}

We abstracted the following data from each study: first author, year of publication, origin, interventions and control groups (drug and dosage), participants' characteristics (number of each group, age) and underlying condition. We used the Newcastle-Ottawa scale to assess the quality of observational studies. This assessment had three sections (selection, comparability and exposure, respectively) and altogether eight items. Studies with a score less than 5 in the present study were excluded from the final analysis [30]. We also evaluated the bias in randomized controlled trials using the Jadad scale, which included the evaluation of randomization, blinding of outcome assessment and description of withdrawals and dropouts. Studies with a Jadad score more than 3 were regarded as high quality and would be included in the final analysis [31].

We analyzed the results of the RCTs, prospective cohort studies and retrospective cohort studies separately to determine whether the results from the non-RCTs affected our calculation of obvious heterogeneity or produced a different outcome from the more robust RCTs. Because there was a mild heterogeneous effect across strata when we compared each study type, respectively, with our main result, we concluded that it was appropriate to combine study types as hypothesis generating rather than confirmatory analysis.

\section{Statistical analysis}

All the meta-analyses were conducted using Review Manager 5.3. The odds ratio (OR) [32] with $95 \%$ confidence intervals (CI) [33] was applied to analyze dichotomous variables, and mean difference (MD) [34] with a 95\% CI was used to analyze continuous ones. If continuous data were presented in mean and standard deviation (SD) [35] of base and final, we would use statistical algorithms to calculate the difference value's mean and SD.

The Chi-square test was used to evaluate the heterogeneity with significance set at the $P<0.05$ level, and the $I^{2}$ statistic value was interpreted as three separate levels: $25 \%$ (low heterogeneity), 50\% (moderate heterogeneity) and 75\% (high heterogeneity) [36]. The random-effect model was conducted when the heterogeneity between studies was too high; otherwise, the fixed-effect model was used [37].

\section{Results}

\section{Literature research and characteristic of studies}

A total of 1329 publications retrieved from the database were scanned for relevance. After reviewing, we included 69 articles that potentially met inclusion criteria. After these full texts were studied, the bibliographies were checked. Overall, 4 RCTs [38-41] and 14 observational studies [42-55] that reached our inclusion criteria constituted the base of our analysis. Three of the observational studies were abstracts that provided necessary data for inclusion in the meta-analysis (Fig. 1, flow chart). The characteristics of the included studies are shown in Table 1.

\section{Quality assessment}

The details of quality assessment based on the NOS are shown in Supplementary Table 1. The Newcastle-Ottawa scale revealed that study qualities varied from 7 to 9 . The qualities of the included studies were good and fair. The quality of the four RCTs we included showed a moderate level. All articles displayed similar baselines and they were then grouped randomly. Patients included in the RCTs had complete follow-up information. The number of withdrawals and the reasons for withdrawal were described in the articles. However, only one RCT adopted the single-blind method, with three articles for three points and one article for five points.

\section{Effects of interventions}

\section{Induced remission rate of exclusive enteral nutrition vs. corticosteroids}

Three RCTs [38, 40, 41] and ten observational studies [42, $43,46-48,50,52-55]$ provided data on the induced remission rate after 6-8 weeks of treatment. Soo et al. [45] calculated the remission rate after 3 months treatment, so data from their paper were excluded. Overall, we analyzed 13 papers including 349 pediatric patients treated with exclusive elemental diet and 311 pediatric patients treated with corticosteroids. The heterogeneity test showed $I^{2}=5 \%$, suggesting that there was a mild heterogeneity between the studies, so we performed the fixed-effect model in our study. We pooled all the results of these trials and found no evidence for a significant difference in the percentage of children 


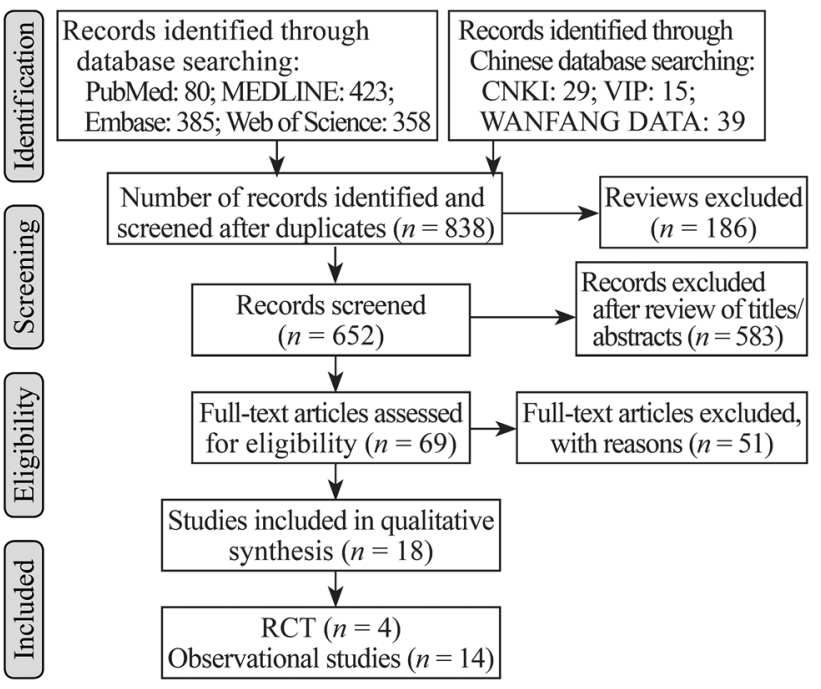

Fig. 1 Flow diagram of trials for inclusion in the systematic review. $n$ number of records

achieving remission between those treated with EEN and those with corticosteroids $(\mathrm{OR}=1.35 ; 95 \%$ CI 0.90, 2.10; $P=0.14$; Fig. 2). Meta-analysis of only RCTs showed that EEN was more effective than corticosteroids $(\mathrm{OR}=2.62$; 95\% CI 0.86, 7.94; $P=0.09$, Supplementary Table 2).

\section{Influence of exclusive enteral nutrition vs. corticosteroids on 1-year relapse rate}

Patients in five observational studies [42, 45, 48, 49, 52] were induced into remission with EEN or corticosteroids, and all of them used thiopurine and/or mesalamine as maintenance therapy. One study [44] that used maintenance enteral nutrition as maintenance therapy was excluded from the meta-analysis. There was only one RCT article, which was excluded as well. Furthermore, we included and analyzed five retrospective cohort studies (158 cases in the EEN group, 154 cases in the corticosteroids group). The metaanalysis of the five retrospective cohort studies also showed that no significant difference existed in the proportions of 1-year relapse rates between the EEN and corticosteroids groups $(\mathrm{OR}=0.57$; $95 \% \mathrm{CI} 0.25,1.29 ; P=0.18$, Fig. 3$)$.

\section{Mucosal healing}

In total, 3 of 18 articles [41, 42, 47] provided information on mucosal healing of patients at the end of induction. The method of Canani et al. [42] defining mucosal healing was different from other articles, so data from the research were excluded. Overall, patients who received EEN were more likely to achieve both endoscopic mucosal healing $(\mathrm{OR}=5.24,95 \%$ CI $2.06,13.37 ; P=0.0005$, Fig. 4$)$ and histological mucosal healing $(\mathrm{OR}=4.78,95 \% \mathrm{CI}$ $1.89,12.08 ; P=0.0009$, Fig. 4$)$ than those who received corticosteroids.

\section{Effects of exclusive enteral nutrition vs. corticosteroids on inflammation}

The data were abstracted from studies that measured PCDAI, CRP and ESR at baseline and at the end of induction in patients receiving EEN and corticosteroids. Then, we used statistical algorithms to calculate the difference value's mean and SD. There was a distinct decline of PCDAI in patients who received EEN compared with those who received corticosteroids $(\mathrm{MD}=-3.67 ; 95 \% \mathrm{CI}-4.91,-2.43$; $P<0.0001$, Fig. 5). However, we found no significant difference in terms of CRP and ESR between patients who received corticosteroids or EEN $(\mathrm{MD}=1.07 ; 95 \% \mathrm{CI} 0.18$, 1.96; $P=0.02$, on $\mathrm{CRP}$, and $\mathrm{MD}=0.60 ; 95 \% \mathrm{CI}-1.82$, 3.03; $P=0.63$, on ESR, Supplementary Figs. 1-2).

\section{Effects of exclusive enteral nutrition vs. corticosteroids on growth}

After induced therapy, patients who received EEN seemed to gain more weight than those who received corticosteroids ( $\mathrm{MD}=1.92 ; 95 \% \mathrm{CI}=0.02,3.83 ; P=0.05$, Supplementary Fig. 3), but height showed no significant difference $(\mathrm{MD}=0.24 ; 95 \% \mathrm{CI}=-1.98,2.45 ; P=0.83$, Supplementary Fig. 4). We also found no significant difference at the 1 -year end point in either height for age ( $\mathrm{MD}=0.45 ; 95 \%$ CI $-0.11,1.02 ; P=0.11$, Supplementary Fig. 5 ) or BMI $(\mathrm{MD}=0.10 ; 95 \% \mathrm{CI}-0.34,0.54 ; P=0.66$, Supplementary Fig. 6).

\section{Discussion}

Crohn's disease is a chronic, progressive disease characterized by repeated relapses after remissions in most cases. The chronic intestinal inflammation that occurs in CD can result in intestinal complications such as strictures, fistulas, and abscesses during the whole period [56, 57]. Medical treatment of CD includes two major parts: induction and maintenance therapy. These phases of treatment involve achieving control of inflammation in a relatively short time and then sustaining that control to prevent patients from relapse. A number of investigators provided much evidence to illustrate the mechanism behind EEN. The primary components underlying the actions of EEN were as follows: inhibiting the expression of inflammatory factors, such as tumor necrosis factor- $\alpha$, interleukin (IL)- 6 and IL- $1 \beta$ [58-60], increasing the release of vascular endothelial growth factor and 


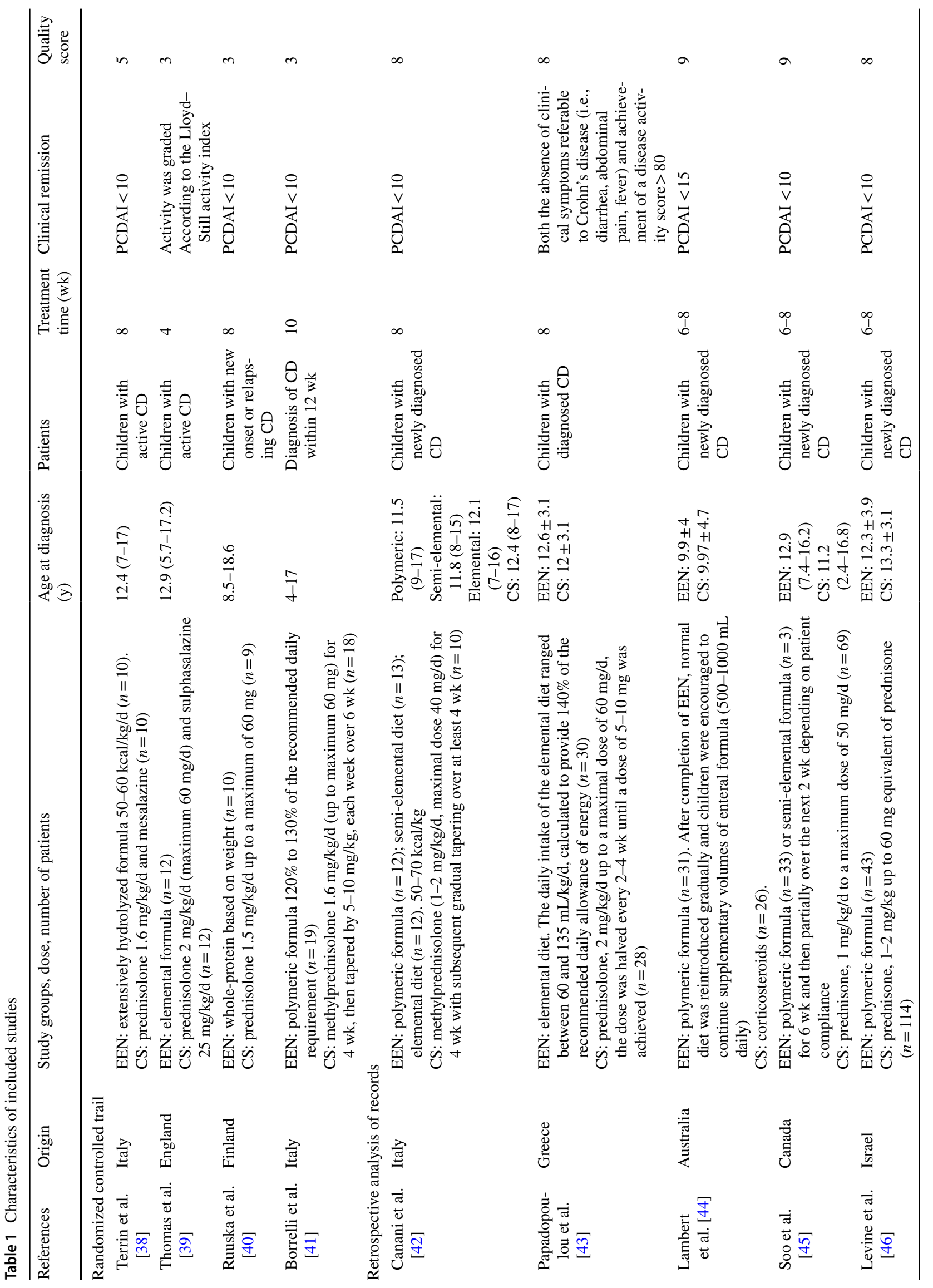




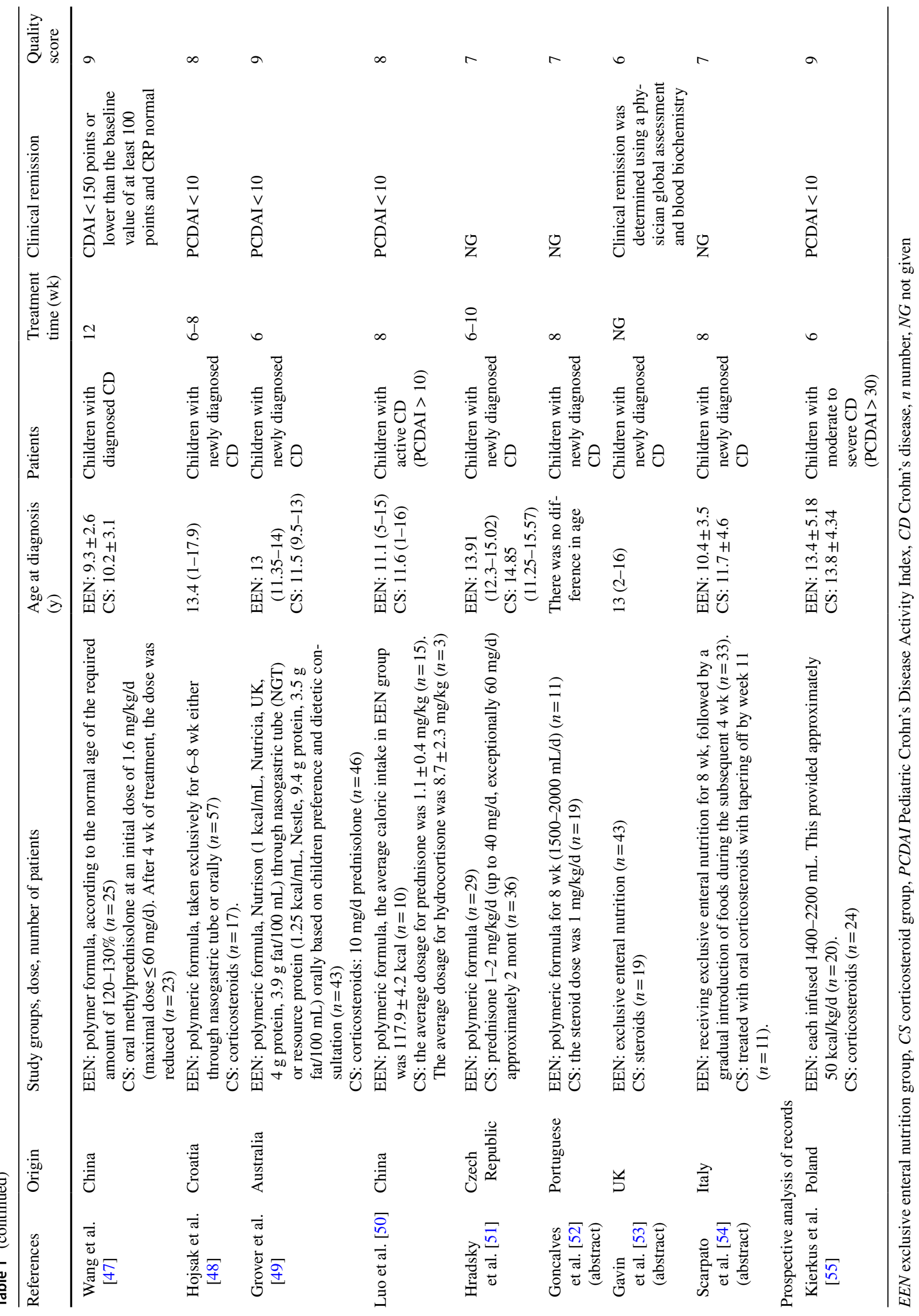




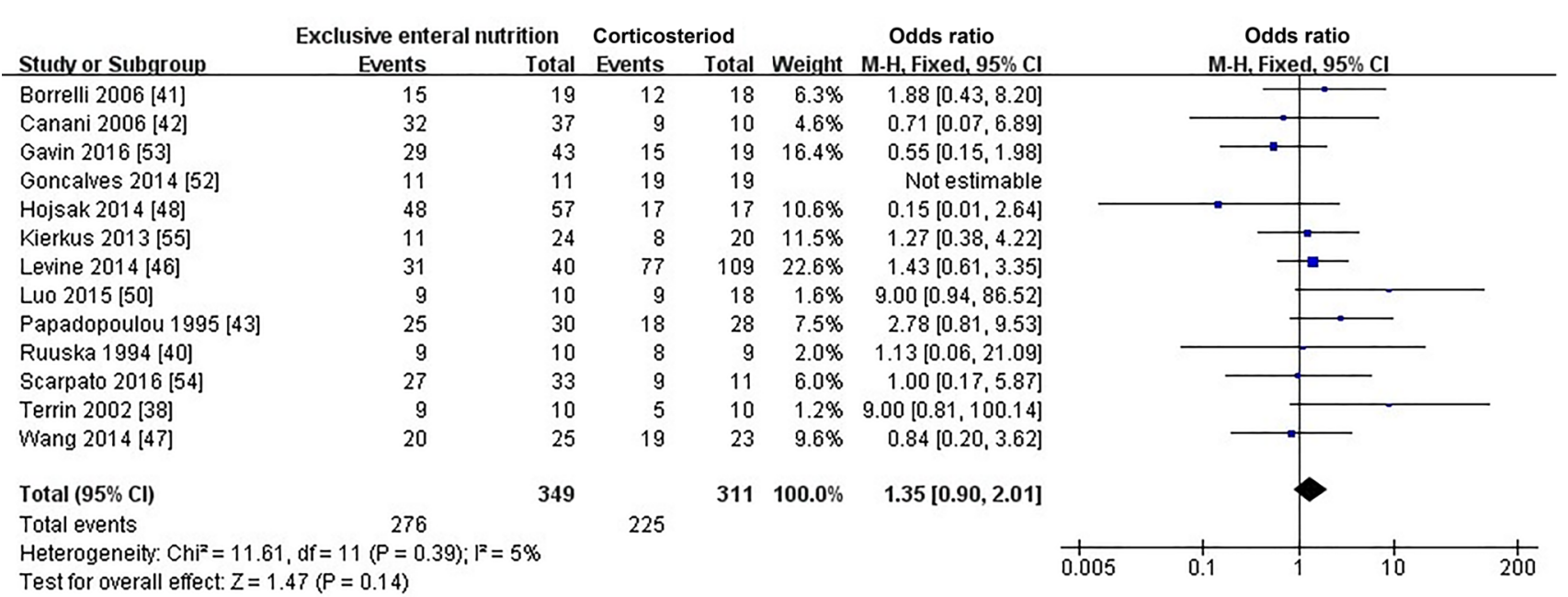

Fig. 2 Forest plot for the comparison of induced remission rates between EEN versus corticosteroids for pediatric Crohn's disease. No significant difference in induced remission rates was found between the EEN and corticosteroid groups $(\mathrm{OR}=1.35$; 95\% CI $0.90,2.10$; $P=0.14)$. EEN exclusive enteral nutrition, $O R$ odds ratio, $C I$ confidence interval, $d f$ degree of freedom

\begin{tabular}{|c|c|c|c|c|c|}
\hline \multirow[b]{2}{*}{ Study or Subgroup } & \multicolumn{2}{|c|}{ Exclusive enteral nutrition } & \multicolumn{2}{|c|}{ Corticosteriod } & \multirow[b]{2}{*}{ Weight } \\
\hline & Events & Total & Events & Total & \\
\hline Canani 2006 [42] & 11 & 37 & 7 & 10 & $16.2 \%$ \\
\hline Goncalves 2014 [52] & 4 & 11 & 10 & 19 & $16.3 \%$ \\
\hline Grover 2015 [49] & 12 & 17 & 21 & 43 & $20.5 \%$ \\
\hline Hojsak 2014 [48] & 24 & $5 ?$ & 12 & 17 & $21.0 \%$ \\
\hline Soo 2013 [45] & 23 & 36 & 51 & 69 & $25.9 \%$ \\
\hline Total $(95 \% \mathrm{Cl})$ & & 158 & & 158 & $100.0 \%$ \\
\hline Total events & 74 & & 101 & & \\
\hline $\begin{array}{l}\text { Heterogeneity: } \operatorname{Tau}^{2}= \\
\text { Test for overall effect: }\end{array}$ & $\begin{array}{l}49 ; C^{2} i^{2}=9.18 \\
=1.35(P=0.1\end{array}$ & $=0$. & $I^{2}=56$ & & \\
\hline
\end{tabular}

Fig. 3 Forest plot for the comparison of 1-year relapse rates between EEN versus corticosteroids for pediatric Crohn's disease. No significant difference in 1-year relapse rates was found between the EEN

transforming growth factor- $\beta$ (TGF- $\beta$ ) to improve intestinal endometrial repairment [61, 62], providing essential amino acids which can promote intestinal mucosal barrier formation $[63,64]$ and activating mucosal immunity, resulting in the maintenance of intestinal homeostasis [65].

Treatments for induced remission in CD patients include corticosteroids, EEN and biologic agents. Recently, people in many countries, such as the Japanese, Europeans, British, and North Americans, have highlighted the remission induction efficacy of EEN on pediatric CD [66-69]. There were two meta-analyses $[15,16]$ hinting that CS was superior to EEN in achieving control of inflammation in acute CD. These two meta-analyses were published in 1995 and 1996, and the retrieval times were between the 1980s and 1990s. The studies included in those two meta-analyses usually used EEN as remission induction therapy for fewer than 4 weeks, whereas the induction time of the studies we included mostly lasted for 6-8 weeks, with only one study lasting 4 weeks.
Odds ratio Odds ratio

Random, $95 \% \mathrm{Cl}$

$0.18[0.04,0.83]$

$0.51[0.11,2.36]$

$2.51[0.76,8.37]$

$0.30[0.09,0.97]$

$0.62[0.26,1.49]$

$0.57[0.25,1.29]$

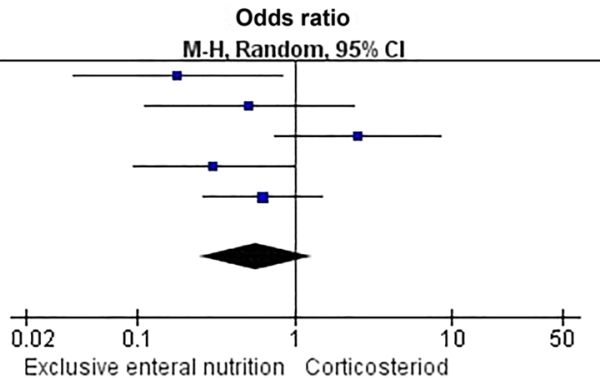

and corticosteroids groups $(\mathrm{OR}=0.57 ; 95 \% \mathrm{CI} 0.25,1.29 ; P=0.18)$. $E E N$ exclusive enteral nutrition, $O R$ odds ratio, $C I$ confidence interval, $d f$ degree of freedom

In addition, those two meta-analyses included patients of all ages, and our meta-analyses focused on pediatric trials. Two other pediatric meta-analyses $[17,18]$ also determined that EEN and corticosteroids were equally effective, similar to our study's conclusions, suggesting that the benefits of EEN may differ between children and adults.

No significant difference was found in 1-year relapse rates between EEN and corticosteroids. In our subgroup metaanalysis of the three articles [15-17], choosing thiopurine as single maintenance therapy had a similar result (EEN vs. CS: OR $=0.93,95 \%$ CI $0.36,2.43 ; P=0.13$ ). The use of thiopurine or mesalamine will impact the results, but it is also unethical to observe relapse rates without any maintenance therapy in child patients.

Recently, many researchers have regarded mucosal healing as a promising therapeutic target, and mucosal healing may substantially modify the course of $\mathrm{CD}$. Mucosal remission was reported to be possibly associated with a sustained 


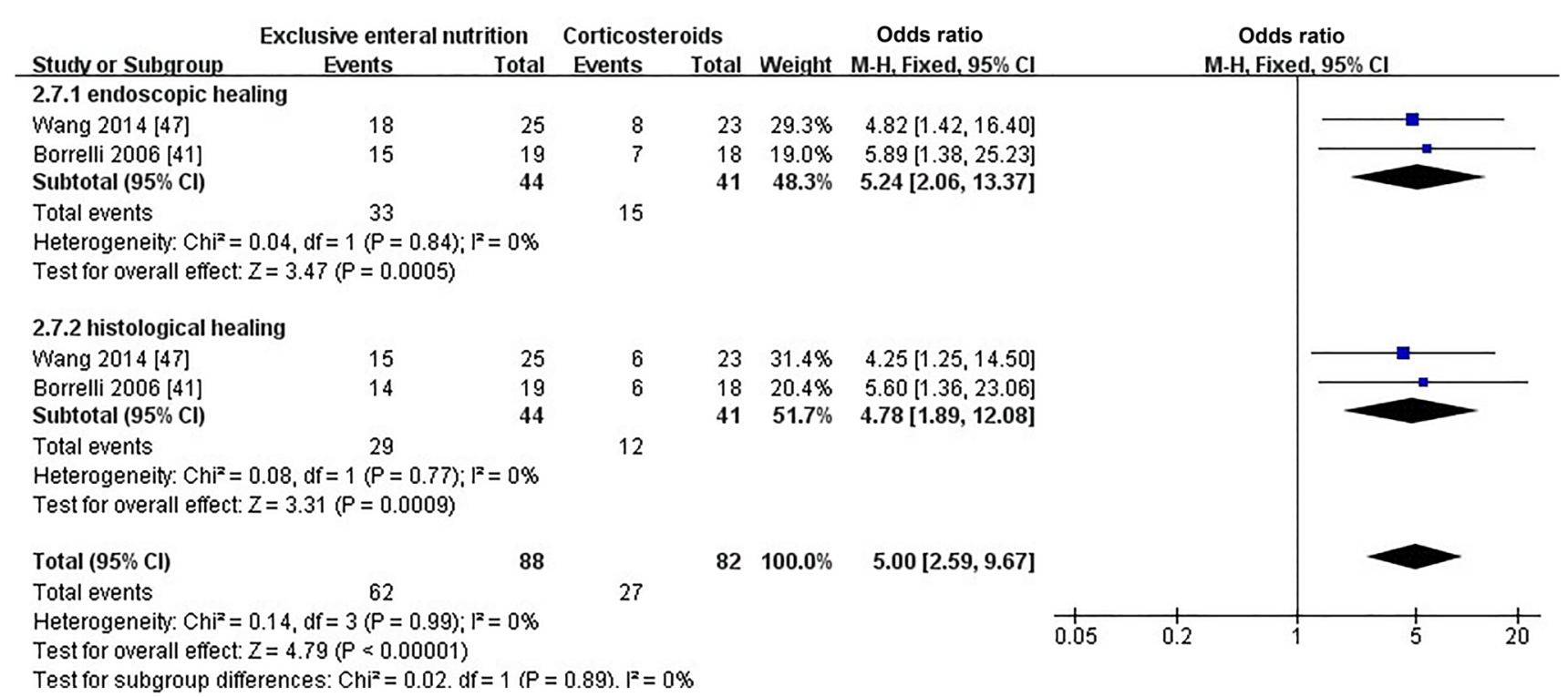

Fig. 4 Forest plot for the comparison of mucosal healing between EEN versus corticosteroids for pediatric Crohn's disease. A significant difference both in endoscopic and histological mucosal healing was found between the EEN and corticosteroid groups $(\mathrm{OR}=5.240$,
95\% CI 2.06, 13.37; $P=0.0005$ and $\mathrm{OR}=4.780,95 \%$ CI 1.89, 12.08; $P=0.0009$, respectively). EEN exclusive enteral nutrition, $O R$ odds ratio, $C I$ confidence interval, $d f$ degree of freedom

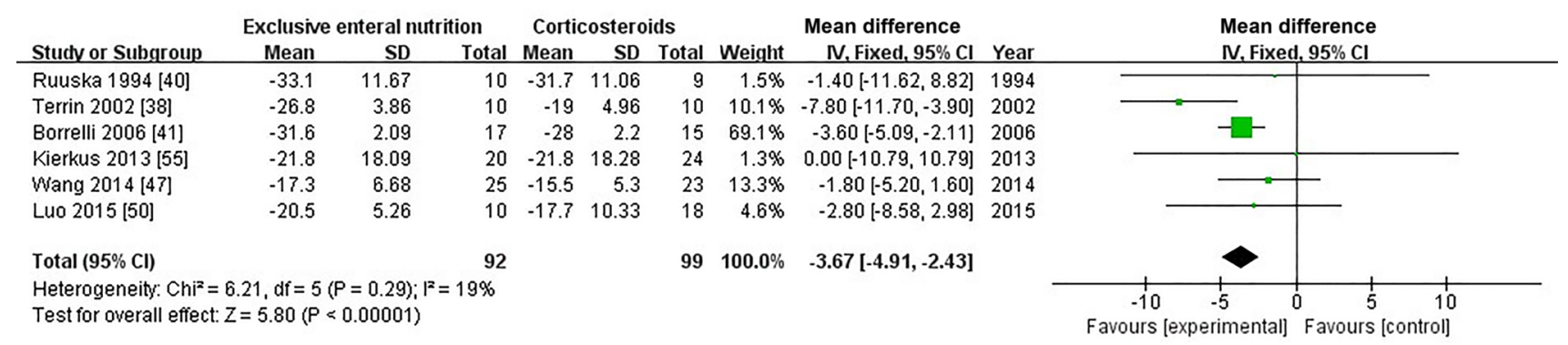

Fig. 5 Forest plot for the comparison of PCDAI between EEN versus corticosteroids for pediatric Crohn's disease. A significant difference in PCDAI was found between the EEN and corticosteroid groups with a standard mean difference of -3.67 (95\% CI - 4.91, - 2.43;

remission rate $[26,70]$. Treatment with steroids was thought to have no positive impacts on mucosal healing [71]. In contrast, some studies reported approximately $19-75 \%$ of children treated with EEN achieved mucosal healing, but these results were unreliable since the definition of mucosal healing among the different studies varied [13, 72-74]. In our meta-analyses, there were two articles that used the CDEIS index to evaluate endoscopic mucosal healing, and the EEN group showed better outcomes than the CS group. A similar outcome was found for histological mucosal healing. A prospective longitudinal cohort study revealed that only complete mucosal healing $(\mathrm{SES}-\mathrm{CD}=0)$ post-EEN induction correlated with a lower sustained remission rate, and the sustained remission rate of near-complete mucosal healing patients (SES 1-3) was similar to that of patients with more
$P<0.00001)$. PCDAI Pediatric Crohn's Disease Activity Index, EEN exclusive enteral nutrition, $C I$ confidence interval, $d f$ degree of freedom

active endoscopic disease [70]. Therefore, there is an urgent need to enlarge sample sizes, achieve cooperation between multiple centers and adopt uniform criteria to prospectively validate whether EEN is more effective in mucosal healing than CS and whether mucosal healing induced by EEN is conducive to sustained remission.

We also found that, after achieving induced remission, patients who received EEN treatment seemed to gain more weight than those who received corticosteroids. This result might be associated with nutritional support from EEN. In addition, we found that inflammation markers, such as CRP and ESR, showed no significant difference. However, patients who received EEN were 3.7 times more likely to have a decline of PCDAI score than those who received corticosteroids. The PCDAI is an index of severity of pediatric 
CD including physical examination, growth parameters and commonly performed laboratory tests [27]. The weight gain in the EEN group may be one factor contributing to PCDAI score decline. Despite the well-described adverse effects that corticosteroids can have on development, growth, and pubertal maturation, particularly if there has been a clinical course of frequent relapses resulting in inadequate nutrition and associated with repeated courses of steroid treatment [75], using corticosteroids as inducing treatment shows similar effects with EEN on the change of height for age and BMI at 1 year. This result may suggest that applying corticosteroids as short-term induction therapy does not have such an adverse impact on long-term growth and development in pediatric patients as expected. However, other growth and development indicators, such as bone age, bone density and gonad development, need to be further evaluated. Most importantly, doctors must still be very prudent in choosing appropriate and effective inducing therapy for $\mathrm{CD}$ pediatric patients to reduce repeated and long-term use of corticosteroids.

Our meta-analysis has several limitations. The observational studies were not designed randomly, and the influence of subjectivity among doctors or parents on the experimental results could not be ruled out; RCT experiments with multicenter, large-scale, strict double-blind and randomly allocated trials should be conducted in the future.

In conclusion, our study suggests the induction remission rate of EEN is similar to that of corticosteroids and that EEN and corticosteroid therapy had no significantly different effects on 1-year relapse rate. However, EEN is superior to corticosteroids in terms of positive effects on short-term mucosal healing and reduction of PCDAI. For these reasons, we recommend EEN as an effective and viable first-line treatment for induction of $\mathrm{CD}$ remission.

Author contributions YY conceptualized and designed the study, designed the data collection instruments, collected data, carried out the initial analyses, drafted the initial manuscript, and reviewed and revised the manuscript. KCC designed the data collection instruments, collected data, carried out the initial analyses, and reviewed and revised the manuscript. JC conceptualized and designed the study, coordinated and supervised data collection, and critically reviewed the manuscript for important intellectual content. All authors approved the final manuscript as submitted and agree to be accountable for all aspects of the work.

Funding No external funding for this manuscript.

\section{Compliance with ethical standards}

Ethical approval None.

Conflict of interest No financial or nonfinancial benefits have been received or will be received from any party related directly or indirectly to the subject of this article.
Open Access This article is distributed under the terms of the Creative Commons Attribution 4.0 International License (http://creativeco mmons.org/licenses/by/4.0/), which permits unrestricted use, distribution, and reproduction in any medium, provided you give appropriate credit to the original author(s) and the source, provide a link to the Creative Commons license, and indicate if changes were made.

\section{References}

1. Rutgeerts P, Lofberg R, Malchow H, Lamers C, Olaison G, Jewell $\mathrm{D}$, et al. A comparison of budesonide with prednisolone for active Crohn's disease. N Engl J Med. 1994;331:842-5.

2. Bernstein CN, Wajda A, Blanchard JF. The clustering of other chronic inflammatory diseases in inflammatory bowel disease: a population-based study. Gastroenterology. 2005;129:827-36.

3. Ventham NT, Kennedy NA, Nimmo ER, Satsangi J. Beyond gene discovery in inflammatory bowel disease: the emerging role of epigenetics. Gastroenterology. 2013;145:293-308.

4. Lees CW, Satsangi J. Genetics of inflammatory bowel disease: implications for disease pathogenesis and natural history. Expert Rev Gastroenterol Hepatol. 2009;3:513-34.

5. Turunen P, Ashorn M, Auvinen A, Iltanen S, Huhtala H, Kolho KL. Long-term health outcomes in pediatric inflammatory bowel disease: a population-based study. Inflamm Bowel Dis. 2009;15:56-62.

6. Benchimol EI, Fortinsky KJ, Gozdyra P, Van den Heuvel M, Van Limbergen J, Griffiths AM. Epidemiology of pediatric inflammatory bowel disease: a systematic review of international trends. Inflamm Bowel Dis. 2011;17:423-39.

7. Benchimol EI, Bernstein CN, Bitton A, Carroll MW, Singh H, Otley AR, et al. Trends in epidemiology of pediatric inflammatory bowel disease in Canada: distributed network analysis of multiple population-based provincial health administrative databases. Am J Gastroenterol. 2017;112:1120-34.

8. Kim HJ, Kim Y, Cho JM, Oh SH, Kim KM. Therapeutic efficacy of oral enteral nutrition in pediatric Crohn's disease: a single center non-comparative retrospective study. Yonsei Med J. 2016;57:1185-91.

9. Voitk AJ, Echave V, Feller JH, Brown RA, Gurd FN. Experience with elemental diet in the treatment of inflammatory bowel disease. Is this primary therapy? Arch Surg. 1973;107:329-33.

10. Ruemmele FM, Veres G, Kolho KL, Griffiths A, Levine A, Escher JC, et al. Consensus guidelines of ECCO/ESPGHAN on the medical management of pediatric Crohn's disease. J Crohns Colitis. 2014;8:1179-207.

11. Whitten KE, Rogers P, Ooi CY, Day AS. International survey of enteral nutrition protocols used in children with Crohn's disease. J Dig Dis. 2012;13:107-12.

12. Frivolt K, Schwerd T, Werkstetter KJ, Schwarzer A, Schatz SB, Bufler P, et al. Repeated exclusive enteral nutrition in the treatment of paediatric Crohn's disease: predictors of efficacy and outcome. Aliment Pharmacol Ther. 2014;39:1398-407.

13. Rubio A, Pigneur B, Garnier-Lengliné H, Talbotec C, Schmitz J, Canioni $\mathrm{D}$, et al. The efficacy of exclusive nutritional therapy in paediatric Crohn's disease, comparing fractionated oral vs. continuous enteral feeding. Aliment Pharmacol Ther. 2011;33:1332-9.

14. Khoshoo V, Reifen R, Neuman MG, Griffiths A, Pencharz PB. Effect of low- and high-fat, peptide-based diets on body composition and disease activity in adolescents with active Crohn's disease. JPEN J Parenter Enteral Nutr. 1996;20:401-5.

15. Ludvigsson JF, Krantz M, Bodin L, Stenhammar L, Lindquist B. Elemental versus polymeric enteral nutrition in paediatric Crohn's 
disease: a multicentre randomized controlled trial. Acta Paediatr. 2004;93:327-35.

16. Rodrigues AF, Johnson T, Davies P, Murphy MS. Does polymeric formula improve adherence to liquid diet therapy in children with active Crohn's disease? Arch Dis Child. 2007;92:767-70.

17. Walker-Smith JA. Dietary treatment of active Crohn's disease. Dietary treatment is best for children. BMJ. 1997;314:1827-8.

18. Heuschkel RB, Menache CC, Megerian JT, Baird AE. Enteral nutrition and corticosteroids in the treatment of acute Crohn's disease in children. J Pediatr Gastroenterol Nutr. 2000;31:8-15.

19. Fernandez-Banares F, Cabre E, Esteve-Comas M, Gassull MA. How effective is enteral nutrition in inducing clinical remission in active Crohn's disease? A meta-analysis of the randomized clinical trials. JPEN J Parenter Enteral Nutr. 1995;19:356-64.

20. Dziechciarz P, Horvath A, Shamir R, Szajewska H. Meta-analysis: enteral nutrition in active Crohn's disease in children. Aliment Pharmacol Ther. 2007;26:795-806.

21. Griffiths AM, Ohlsson A, Sherman PM, Sutherland LR. Metaanalysis of enteral nutrition as a primary treatment of active Crohn's disease. Gastroenterology. 1995;108:1056-67.

22. Messori A, Trallori G, D’Albasio G, Milla M, Vannozzi G, Pacini F. Defined-formula diets versus steroids in the treatment of active Crohn's disease: a meta-analysis. Scand J Gastroenterol. 1996;31:267-72.

23. Cohen SA, Gold BD, Oliva S, Lewis J, Stallworth A, Koch B, et al. Clinical and mucosal improvement with specific carbohydrate diet in pediatric Crohn disease. J Pediatr Gastroenterol Nutr. 2014;59:516-21.

24. Baert F, Moortgat L, Van Assche G, Caenepeel P, Vergauwe $\mathrm{P}$, De Vos M, et al. Mucosal healing predicts sustained clinical remission in patients with early-stage Crohn's disease. Gastroenterology. 2010;138:463-8; quiz e10-1.

25. Faubion WA Jr, Loftus EV Jr, Harmsen WS, Zinsmeister AR, Sandborn WJ. The natural history of corticosteroid therapy for inflammatory bowel disease: a population-based study. Gastroenterology. 2001;121:255-60.

26. Grover Z, Muir R, Lewindon P. Exclusive enteral nutrition induces early clinical, mucosal and transmural remission in paediatric Crohn's disease. J Gastroenterol. 2014;49:638-45.

27. Hyams JS, Ferry GD, Mandel FS, Gryboski JD, Kibort PM, Kirschner BS, et al. Development and validation of a pediatric Crohn's disease activity index. J Pediatr Gastroenterol Nutr. 1991;12:439-47.

28. Mary JY, Modigliani R. Development and validation of an endoscopic index of the severity for Crohn's disease: a prospective multicentre study. Groupe d'Etudes Therapeutiques des Affections Inflammatoires du Tube Digestif (GETAID). Gut. 1989;30:983-9.

29. D'Haens GR, Geboes K, Peeters M, Baert F, Penninckx F, Rutgeerts P. Early lesions of recurrent Crohn's disease caused by infusion of intestinal contents in excluded ileum. Gastroenterology. 1998;114:262-7.

30. Wells GA, Shea B, O'Connell D, Peterson J, Welch V, et al. The Newcastle-Ottawa Scale (NOS) for assessing the quality of nonrandomised studies in meta-analyses. 2003. http://www.ohri.ca/ programs/clinical_epidemiology/oxford.asp. Accessed 5 May 2012.

31. Jadad AR, Moore RA, Carroll D, Jenkinson C, Reynolds DJ, Gavaghan DJ, et al. Assessing the quality of reports of randomized clinical trials: is blinding necessary? Control Clin Trials. 1996;17:1-12.

32. Wirtz MA. Basic statistical measures for dichotomous data formats: risk, odds, logits, relative risk. odds ratio. Die Rehabil. 2017;56:264-71.

33. Wolfe R, Abramson MJ. Modern statistical methods in respiratory medicine. Respirology. 2014;19:9-13.
34. Takeshima N, Sozu T, Tajika A, Ogawa Y, Hayasaka Y, Furukawa TA. Which is more generalizable, powerful and interpretable in meta-analyses, mean difference or standardized mean difference? BMC Med Res Methodol. 2014;14:30.

35. Lee DK, In J, Lee S. Standard deviation and standard error of the mean. Korean J Anesthesiol. 2015;68:220-3.

36. Higgins JP, Thompson SG. Quantifying heterogeneity in a metaanalysis. Stat Med. 2002;21:1539-58.

37. Lau J, Ioannidis JP, Schmid CH. Quantitative synthesis in systematic reviews. Ann Intern Med. 1997;127:820-6.

38. Terrin G, Canani RB, Ambrosini A, Viola F, De Mesquita MB, Di Nardo G, et al. A semielemental diet (Pregomin) as primary therapy for inducing remission in children with active Crohn's disease. Ital J Pediatr. 2002;28:401-5.

39. Thomas AG, Taylor F, Miller V. Dietary intake and nutritional treatment in childhood Crohn's disease. J Pediatr Gastroenterol Nutr. 1993;17:75-81.

40. Ruuska T, Savilahti E, Maki M, Ormala T, Visakorpi JK. Exclusive whole protein enteral diet versus prednisolone in the treatment of acute Crohn's disease in children. J Pediatr Gastroenterol Nutr. 1994;19:175-80.

41. Borrelli O, Cordischi L, Cirulli M, Paganelli M, Labalestra V, Uccini S, et al. Polymeric diet alone versus corticosteroids in the treatment of active pediatric Crohn's disease: a randomized controlled open-label trial. Clin Gastroenterol Hepatol. 2006;4:744-53.

42. Berni Canani R, Terrin G, Borrelli O, Romano MT, Manguso F, Coruzzo A, et al. Short- and long-term therapeutic efficacy of nutritional therapy and corticosteroids in paediatric Crohn's disease. Dig Liver Dis. 2006;38:381-7.

43. Papadopoulou A, Rawashdeh M, Brown G, McNeish A, Booth I. Remission following an elemental diet or prednisolone in Crohn's disease. Acta Paediatr. 1995;84:79-83.

44. Lambert B, Lemberg DA, Leach ST, Day AS. Longer-term outcomes of nutritional management of Crohn's disease in children. Dig Dis Sci. 2012;57:2171-7.

45. Soo J, Malik BA, Turner JM, Persad R, Wine E, Siminoski K, et al. Use of exclusive enteral nutrition is just as effective as corticosteroids in newly diagnosed pediatric Crohn's disease. Dig Dis Sci. 2013;58:3584-91.

46. Levine A, Turner D, Pfeffer Gik T, Amil Dias J, Veres G, Shaoul $\mathrm{R}$, et al. Comparison of outcomes parameters for induction of remission in new onset pediatric Crohn's disease: evaluation of the porto IBD group "growth relapse and outcomes with therapy" (GROWTH CD) study. Inflamm Bowel Dis. 2014;20:278-85.

47. Wang L, Jin X, Zhao H, Liu S, Gong Y, Wu J, et al. Enteral nutrition versus corticosteroids in treatment of active pediatric Crohn's disease. Clin J Med Off. 2014;12:1227-30.

48. Hojsak I, Pavic AM, Misak Z, Kolacek S. Risk factors for relapse and surgery rate in children with Crohn's disease. Eur J Pediatr. 2014;173:617-21.

49. Grover Z, Lewindon P. Two-year outcomes after exclusive enteral nutrition induction are superior to corticosteroids in pediatric Crohn's disease treated early with thiopurines. Dig Dis Sci. 2015;60:3069-74.

50. Luo Y, Yu J, Zhao H, Lou J, Chen F, Peng K, et al. Shortterm efficacy of exclusive enteral nutrition in pediatric Crohn's disease: practice in China. Gastroenterol Res Pract. 2015;2015:428354.

51. Hradsky O, Copova I, Zarubova K, Nevoral J, Bronsky J. Time to relapse in children with Crohn's disease treated with azathioprine and nutritional therapy or corticosteroids. Dig Dis Sci. 2016;61:2041-50.

52. Goncalves JP, Tavares M, Quaresma L, Rego H, Ratola A, Trindade E, et al. Impaired remission in pediatric Cronh's disease-are steroids to blame? Gastroenterology. 2014;146:S-782. 
53. Gavin J, Ashton JJ, Heather N, Marino LV, Beattie RM. Crohns disease: initial treatment and outcomes at 12 months. Arch Dis Child. 2016;101:A24.

54. Scarpato E, Strisciuglio C, Martinelli M, Tortora C, Cenni S, Serra MR, et al. Does exclusive enteral nutrition affect the clinical course in paediatric Crohn's disease patients? J Pediatr Gastroenterol Nutr. 2016;62:702.

55. Kierkus J, Szymanska S, Szczepanski M, Wiernicka A, Szymanska E, Matuszczyk M, et al. The efficacy of total enteral nutrition in inducing remission and improving nutritional status in children with moderate to severe Crohn's disease. J Crohns Colitis. 2013;8:57-61.

56. Kim SC, Ferry GD. Inflammatory bowel diseases in pediatric and adolescent patients: clinical, therapeutic, and psychosocial considerations. Gastroenterology. 2004;126:1550-60.

57. Vernier-Massouille G, Balde M, Salleron J, Turck D, Dupas JL, Mouterde O, et al. Natural history of pediatric Crohn's disease: a population-based cohort study. Gastroenterology. 2008;135:1106-13.

58. DiFedele LM, He J, Bonkowski EL, Han X, Held MA, Bohan A, et al. Tumor necrosis factor alpha blockade restores growth hormone signaling in murine colitis. Gastroenterology. 2005;128:1278-91.

59. Beattie RM, Camacho-Hubner C, Wacharasindhu S, Cotterill AM, Walker-Smith JA, Savage MO. Responsiveness of IGF-I and IGFBP-3 to therapeutic intervention in children and adolescents with Crohn's disease. Clin Endocrinol (Oxf). 1998;49:483-9.

60. Bannerjee K, Camacho-Hubner C, Babinska K, Dryhurst KM, Edwards R, Savage MO, et al. Anti-inflammatory and growthstimulating effects precede nutritional restitution during enteral feeding in Crohn disease. J Pediatr Gastroenterol Nutr. 2004;38:270-5.

61. Wedrychowicz A, Kowalska-Duplaga K, Jedynak-Wasowicz U, Pieczarkowski S, Sladek M, Tomasik P, et al. Serum concentrations of VEGF and TGF- $\beta 1$ during exclusive enteral nutrition in IBD. J Pediatr Gastroenterol Nutr. 2011;53:150-5.

62. Koch AE, Harlow LA, Haines GK, Amento EP, Unemori EN, Wong WL, et al. Vascular endothelial growth factor. A cytokine modulating endothelial function in rheumatoid arthritis. J Immunol. 1994;152:4149-56.

63. Blum S, Brito F. Current state of the art of medical foods. Nestle Nutr Inst Workshop Ser. 2014;79:141-51.
64. Nichols NL, Bertolo RF. Luminal threonine concentration acutely affects intestinal mucosal protein and mucin synthesis in piglets. J Nutr. 2008;138:1298-303.

65. Keenan JI, Hooper EM, Tyrer PC, Day AS. Influences of enteral nutrition upon CEACAM6 expression by intestinal epithelial cells. Innate Immun. 2014;20:848-56.

66. Konno M, Kobayashi A, Tomomasa T, Kaneko H, Toyoda S, Nakazato Y, et al. Guidelines for the treatment of Crohn's disease in children. Pediatr Int. 2006;48:349-52.

67. Sandhu BK, Fell JM, Beattie RM, Mitton SG, Wilson DC, Jenkins $\mathrm{H}$. Guidelines for the management of inflammatory bowel disease in children in the United Kingdom. J Pediatr Gastroenterol Nutr. 2010;50(Suppl 1):S1-13.

68. Lochs H, Dejong C, Hammarqvist F, Hebuterne X, Leon-Sanz M, Schutz T, et al. ESPEN guidelines on enteral nutrition: gastroenterology. Clin Nutr. 2006;25:260-74.

69. Critch J, Day AS, Otley A, King-Moore C, Teitelbaum JE, Shashidhar H. Use of enteral nutrition for the control of intestinal inflammation in pediatric Crohn disease. J Pediatr Gastroenterol Nutr. 2012;54:298-305.

70. Grover Z, Burgess C, Muir R, Reilly C, Lewindon PJ. Early mucosal healing with exclusive enteral nutrition is associated with improved outcomes in newly diagnosed children with luminal Crohn's disease. J Crohns Colitis. 2016;10:1159-64.

71. Neurath MF, Travis SP. Mucosal healing in inflammatory bowel diseases: a systematic review. Gut. 2012;61:1619-35.

72. Afzal NA, Van Der Zaag-Loonen HJ, Arnaud-Battandier F, Davies S, Murch S, Derkx B, et al. Improvement in quality of life of children with acute Crohn's disease does not parallel mucosal healing after treatment with exclusive enteral nutrition. Aliment Pharmacol Ther. 2004;20:167-72.

73. Fell JM, Paintin M, Arnaud-Battandier F, Beattie RM, Hollis A, Kitching P, et al. Mucosal healing and a fall in mucosal proinflammatory cytokine mRNA induced by a specific oral polymeric diet in paediatric Crohn's disease. Aliment Pharmacol Ther. 2000;14:281-9.

74. Beattie RM, Schiffrin EJ, Donnet-Hughes A, Huggett AC, Domizio P, MacDonald TT, et al. Polymeric nutrition as the primary therapy in children with small bowel Crohn's disease. Aliment Pharmacol Ther. 1994;8:609-15.

75. Brain CE, Savage MO. Growth and puberty in chronic inflammatory bowel disease. Bailliere's Clin Gastroenterol. 1994;8:83-100. 